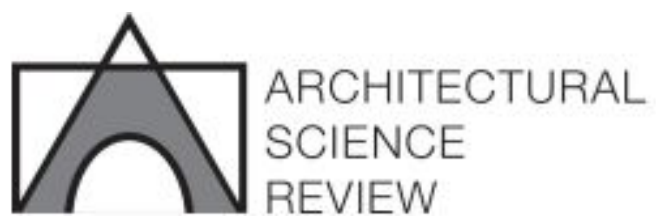

\title{
A comparison between preference judgments of curvature and sharpness in architectural façades
}

\begin{tabular}{|r|l|}
\hline Journal: & Architectural Science Review \\
\hline Manuscript ID & ASRE-2018-0091.R2 \\
\hline Manuscript Type: & Original Article \\
\hline Keywords: & $\begin{array}{l}\text { architectural façades, curvature, aesthetics, visual comfort, image } \\
\text { analysis }\end{array}$ \\
\hline \multicolumn{2}{|l}{} \\
\hline
\end{tabular}

\section{SCHOLARONE \\ Manuscripts}




\begin{tabular}{lllll}
\hline Façades & A & B & C & D \\
\hline A & - & 21 & 22 & 21 \\
B & 3 & - & 19 & 17 \\
C & 2 & 5 & - & 6 \\
D & 3 & 7 & 18 & - \\
\hline
\end{tabular}

Table 1. The table reports the dominance matrix for the paired-comparison task. 
1 A comparison between preference judgments of curvature and

2 sharpness in architectural façades

3

4 Word count: 5.976 (including bibliography: 7.547) 


\section{A comparison between preference judgments of curvature and 7 sharpness in architectural façades}

Can curvature drive preference for architectural façades and their perceived familiarity, complexity, stability or approachability? In this study we aimed to investigate if the well-known preference for curvature can be extended to the architectural domain. We generated four different versions of the same reference building, varying only the amount of curvature of the façade. Twenty-four participants 1) made a preference forced-choice task between pairs of stimuli; 2) ranked all stimuli from the most to the least preferred; 3) evaluated each stimulus on different psychological variables. Multidimensional scaling on forced choices showed that the curved façade was the most preferred. Multidimensional unfolding on the ranking task showed that the majority expressed higher preferences for the curved facades compared to sharp-angled and rectilinear ones. Ratings on different psychological variables gave supporting evidence for curvature significantly influencing liking and approaching judgments. We then processed the stimuli with a dynamical model of the visual cortex and a model that characterises discomfort in terms of adherence to the statistics of natural images. Results from these image analyses matched behavioural data. We discuss the implications of the findings on our understanding of human preferences, which are intrinsically dynamic and influenced by context and experience.

Keywords: architectural façades; curvature; aesthetics; visual comfort; image analysis

\section{Introduction}

Architects frame space, design geometries and study buildings' proportions to convey ideas and emotionally engage the visitor. The $20^{\text {th }}$ century unbuilt project of the Italian architects P. Lingeri and G. Terragni (1938), the Danteum, is a striking example of a building planned to have no other function except to tell the story of Dante's Divine Comedy (Figure 1). The idea that the structure and shape of the environment we live in can influence our social behaviour and our affective state can be traced up to Vitruvius (15 B.C.). Principles of utilitas (functionality), firmitas (stability) and venustas 
36 (aesthetics) influenced the most prominent architects and artists of Italian Renaissance:

37 Alberti, Palladio, Brunelleschi, Borromini, Bramante and Leonardo da Vinci. Vitruvian terms like order, proportion and symmetry are still a reference point for experts nowadays. For example, in the Design Quality Indicator (DQI; Gann, Salyer \& Whyte, 2003) authors started directly from the three old Vitruvian principles to develop the

41 three modern concepts of: function, build-quality and impact.
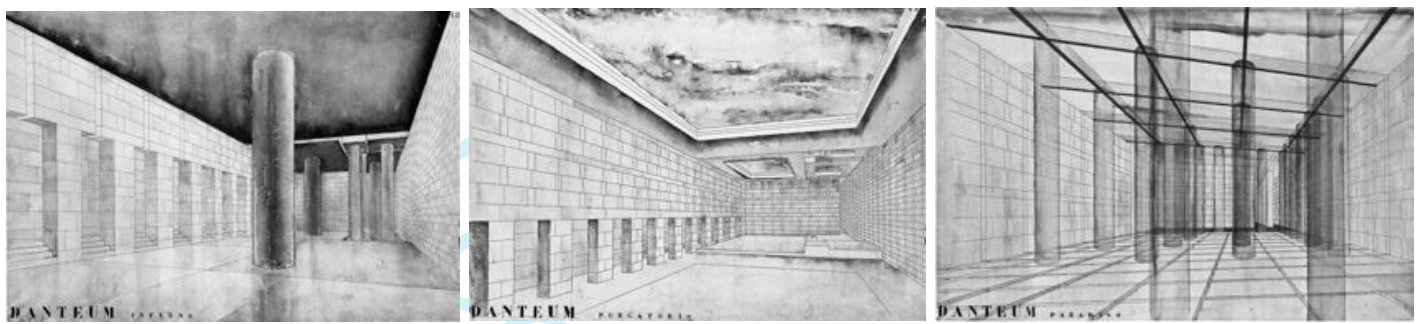

Figure 1. From left to right: perspective of the Hell, the Purgatoire and the Heaven rooms of the Danteum's project by P. Lingeri, G. Terragni (1938, Archivio Pietro Lingeri, Milano). Retrieved from:

http://www.fupress.net/index.php/oi/article/viewFile/19687/18808

In the contemporary era, we can outline two main trends characterising architecture design: 1) the 'modernist' approach, inspired by the creed 'form ever follows function' (Sullivan, 1896) that prioritises the function of a building over its aesthetics; and 2) the 'human-centred design' approach, characterised by the effort to capture and potentially predict the impact of architecture and urban design on human behaviour (Shaftoe 2008; Gutman 2009; Zhang \& Dong, 2009). Since the 70's, approaches like organic architecture (Wright, 1958; Hildebrand, 1991, 1999), bio-architecture (Aguilar, 2003) and biomimicry (Gendall, 2009) started to flourish, combining the use of sustainable resources to basic configurations developed from existing natural shapes and promoting the buildings' integration in nature. Theoretical frameworks interpreting environmental preference for landscapes and built environments (Appleton, 1992, 1996; Hildebrand, 
58

59

60

1991) stressed the potential positive impact that particular combinations of shapes might have on users' emotional experience of space (Lidwell et al. 2010; Lippmann 2010).

The main aim of this study is to investigate the role of geometry in the architecture domain, with a particular focus on the influence of curvature in driving human's preferences. We will outline key findings from literature to create a theoretical context for relevant issues that can be extended to the field of architectural design and urban planning.

\section{The curvature effect}

In psychology, the 'curvature effect' is a well-known and consistent phenomenon (Bar \& Neta, 2006, 2007; Silvia \& Barona, 2009; Leder et al., 2011; Palumbo et al., 2015; Bertamini et al., 2016; Vartanian et al., 2013, 2015), yet still not well understood.

In their classical studies, Bar and Neta $(2006,2007)$ showed that objects and abstract shapes were preferred in their curved version compared to the sharp-angled one and a significantly greater activation of the amygdala for the sharp-angled objects compared to their curved version (Bar \& Neta, 2007). Due to the neutral valence of their stimuli, the authors interpreted the amygdala activation as threat-related, suggesting that sharp-angled contours convey a sense of threat per se and that preference for curvature is a by-product of disliking sharpness (Bar \& Neta, 2007). However, this interpretation has been challenged by other studies using different methodologies, addressing implicit associations and approach/avoidance responses to curvature (Palumbo et al., 2015). In their second experiment, Palumbo et al. (2015) showed that participants were faster and more accurate when the task was to move a human-stick figure towards curved shapes, but there was no difference in the RTs when the task was to approach or avoid sharp- 
82

83

84

angled shapes. The authors conclude that curvature might be preferred for its intrinsic aesthetically pleasing properties, but also be influenced by the emotional valence of positive, safe and female concepts shown to be implicitly associated with curved shapes -as they showed in the first experiment (Palumbo et al., 2015).

In the extensive review on the theme, Gómez-Puerto, Munar and Nadal (2016) identify two main approaches that shaped the research of the past two centuries:

1) the first one, focusing on the physical properties and the perceptual mechanisms involved in preference for curvature, explaining the phenomenon from a sensorimotor-based or a valuation-based perspective;

2) and the other oriented towards the investigation of the origins and the possible function of this preference, divided between culturally influenced or biologically determined explanations.

Moreover, research has shown that preference for curvature can be mediated by the emotional valence of the stimuli (Leder at al., 2011), participants' expertise (Silvia and Barona, 2009) and cultural context or aesthetic Zeitgeist (Leder \& Carbon, 2005;

Carbon, 2010). Hess and colleagues (2013) showed that abstract sharp-angled shapes could also modulate perceived aggressiveness of a face as well as our social behaviour.

While assembling a puzzle, participants tended to judge the resulting faces as more aggressive if the puzzle was made by sharp-angled compared to curved elements. In the second experiment they showed that participants were more likely to make an aggressive decision in a role-playing trust game if sharp-angled shapes compared to curve shapes decorate the experimental setting. Gómez-Puerto et al. (2016) conclude that there is enough evidence in the field to support preference for curvature as being both the result of a learnt process as well as an evolved one. 
106 Preference for curvature in architecture: what do we know so far?

107 Experimental research reported contrasting results also when using architecture images.

108 In the fMRI studies conducted by Vartanian and colleagues $(2013,2015)$, participants

109 looked at images of architectural interiors and then judged them on different

110 psychological variables. The study reported that curved interiors were more likely to be

111 perceived as beautiful compared to rectilinear ones, but the geometry was not a critical

112 factor for approachability decisions. Neuroanatomical results showed that looking at

113 curved spaces activated the anterior cingulate cortex (ACC) exclusively, a brain region

114 which is known to be linked to reward and being a core circuit for aesthetic processing.

115 In contrast, rectilinear interiors did not show a significant amygdala activation, as

116 previously found by Bar and Neta (2007). The authors put forward the hypothesis that,

117 in architecture, sharp-angled contours may have lost their threatening valence, as an

118 effect of mere exposure (Marks \& Dar, 2000; Zajonc, 2001).

119 If we exclude the studies by Vartanian et al. $(2013,2015)$, there is a very limited

120 number of researches that explicitly controlled for the amount of curvature/sharpness of

121 the stimuli involved, especially when representing an artificial environment. Leder and

122 Carbon (2005) tried to isolate the cultural influence on preference for curvature using a

123 series of sketches inspired by actual car design, manipulating their complexity,

124 innovativeness and amount of curvature. Their findings confirmed the role of curvature

125 in significantly influencing attractiveness ratings, with a relatively small impact of

126 participants' design knowledge. In another study on car design, Carbon (2010) provided

127 empirical evidence for the dynamic nature of this preference by explicitly instructing

128 participants about the cultural context and historical design tends (Zeitgeist effect).

129 After adaptation to futuristic car design, perceived innovativeness became a better

130 predictor for participants' liking judgments compared to curvature (Carbon, 2010). 
131 Research in environmental psychology has not provided conclusive results about the

132 importance of geometry in architecture either. In the meta-analysis conducted by Dosen

133 \& Ostwald (2016) only five out of the thirty-four analysed studies directly manipulated

134 the geometry of the space, using environments' computational simulations.

In a recent study, Shemesh et al. (2016) validated a new methodology

136 combining psychological and neurophysiological measures (EEG) with Virtual Reality

137 (VR) in order to capture in a more controlled way the dimension of spatial interaction

138 with the environment. This is one of the very first studies, to the best of our knowledge,

139 directly controlling for the global geometry and the symmetry of the architectural space

140 presented in the experiment. They created four types of virtual environments,

141 controlling for curvature and symmetry. They analysed the EEG data using a two-steps

142 manifold learning technique: the first step identified the EEG channels relevant for

143 geometry processing (Lederman \& Talmon, 2015); while the second step analysed the

144 activity of those selected channels (Talmon et al. 2015). The study showed encouraging

145 results for differentiating brain activity in response to the different geometries. The

146 authors found that curvature, but not symmetry, had a significant impact on VR users'

147 preference overall, with a significant effect of participants' design expertise: non-

148 experts rated curved spaces as more interesting compared to experts.

149 It is important to point out how previous research showed contrasting results on

150 the role of expertise in modulating preference for curvature: Silvia and Barona (2009)

151 reported a significant interaction between expertise and curvature: in the first

152 experiment with simple polygons the effect was stronger for novices; while in the

153 second experiment, that used more complex shapes, experts showed a greater preference

154 for curvature. Mass et. al. (2000) reported that architectural façades judged as beautiful

155 were also perceived as intimidating by lay people (Maass et al., 2000), and Cotter et al. 
156 (2017) showed how preference for curvature is linked with art expertise and openness to 157 experience personality trait.

\section{What can we learn from image analysis?}

159 One of the key arguments used by the biologically determined explanations is

160 that curved lines are more occurring in nature. From this assumption derives that sharp-

161 angled shapes are perceived as threatening because they are difficult to find in organic

162 environments (Gómez-Puerto et al., 2016). We know that natural images, namely

163 images of natural scenes, have special statistical properties, and that these properties can

164 be processed more efficiently by the human visual system (Field, 1987; Geisler 2007).

165 Based on these characteristics, Penacchio and Wilkins (2015) developed an algorithm

166 that robustly predicts visual discomfort in terms of adherence to the statistics of natural

167 images: the more an image deviates from the statistics of natural images, the more likely

168 it is to be judged as uncomfortable to look at. Repetitive patterns such as high contrast

169 gratings, whose image statistics strongly deviate from the statistics of natural images,

170 are particularly uncomfortable to look at, especially if the spatial frequencies involved

171 correspond to those best perceived by the human visual system (Fernandez \& Wilkins,

172 2008; Juricevic, Land, Wilkins, \& Webster, 2010; Penacchio \& Wilkins, 2015).

173 Computational models suggest that detrimental patterns and images with unnatural

174 statistics are processed less efficiently by the brain as they cause a denser response

175 (more neurons firing at the same time) in the visual system (Hibbard \& O'Hare, 2014;

176 Penacchio et al., 2016), which can be at the origin of visual discomfort. Le et al. (2016)

177 reported that images of urban scenes with statistical properties that deviate from the

178 typical statistical properties of natural scenes were associated with a higher

179 haemodynamic response in the visual cortex. They also found that judgments of visual

180 discomfort from real scenes were matched to judgments from images of these scenes, 
181 suggesting that this measure could be integrated into the design practice of urban scenes

182 to avoid constructions with detrimental consequences for brain metabolism, and also for

183 health and wellbeing.

184 Literature offers useful insights about curved shapes driving our preferences for

185 built environments and objects surrounding us, but also highlights the need to

186 investigate the role played by individual differences (e.g.: personality traits) and explicit

187 knowledge (e.g.: expertise) in modulating this effect. We can highlight four limits of the

188 body of research reported so far, relevant when trying to generalise these findings to the

189 architecture domain:

190 (1) most of research used very simple or abstract stimuli;

191 (2) often the stimuli are presented on computer screens, making difficult to

192 generalise results to real spatial interaction with architectural geometries;

193 (3) the studies measured primarily liking judgments;

194 (4) there are technical issues in the control for global and local amount of curvature

195 introduced in more complex stimuli, especially when representing architectural

196 spaces, as usually researchers in psychology do not have expertise on 3D

197 modelling.

198 We suggest that those limits can be addressed directly engaging in a dialog with

199 professional architects, defining research questions relevant for both psychological

200 science and architecture design. Collaborating with experts in architecture allows to

201 create stimuli more ecologically valid and to have a better control the geometry of the

202 built space, rather than trying to match or modify pictures of already existing buildings.

203 We believe that a multidisciplinary approach is needed when studying complex

204 phenomena like the curvature effect, to explain its multiple aspects and implications. 
205 Starting from those preliminary considerations, in the present study we wanted to test

206 the robustness of the 'curvature effect' not only exploring judgements of façades as

207 isolated stimuli, but also directly comparing different versions of the same building

208 (controlling for local and global features). We collected preferences with three different

209 methods: a forced-choice task, ratings on a series of psychological variables for each

210 façade and a classification task.

\section{Material and Methods}

\section{Participants}

213 Twenty-four female participants gave informed consent before taking part in the

214 experiment. All were volunteers and were recruited from the student population of the

215 School of Education of University of Roma Tre. All had normal or corrected-to-normal

216 vision. The experiment was conducted in accordance with the Declaration of Helsinki

217 (2008). Preference for curvature has been shown not to be subjected by gender

218 differences (Frantz \& Miranda, 1975; Jadva et al., 2010; Palumbo et al., 2015), so we

219 have evidence to support the fact that having a sample made of all women will not bias

220 our data.

\section{$221 \quad$ Stimuli}

222 We adopted a similar approach to Leder and Carbon (2005) and controlled for both

223 global and local features of our stimuli, gradually increasing the amount of curvature

224 introduced in the architectural façade. Knowing that positive emotional valence

225 modulates the preference for curved objects (Leder et al., 2011), we wanted to control

226 the affective valence associated with the architectural style of our stimuli. Previous

227 studies (Mastandrea, Bartoli \& Carrus, 2010; Chirumbolo, Brizi et al., 2014; 
228 Mastandrea, \& Maricchiolo, 2014) showed that lay people find easier to implicitly

229 associate figurative art, classical architecture and design objects to positive concepts

230 compared to abstract art and modern architecture. We choose as reference building the

231 Oratorio dei Filippini (Oratory of Saint Phillip Neri, 1637-1650) by Francesco

232 Borromini (Figure 2), one of the most representative architects of the Baroque style,

233 close to the classical buildings used in previous research investigating affective valence

234 of architecture design (Mastandrea, Bartoli \& Carrus, 2010).

235

236

237

238

239

240

241

242

243

244 stimuli as follows:

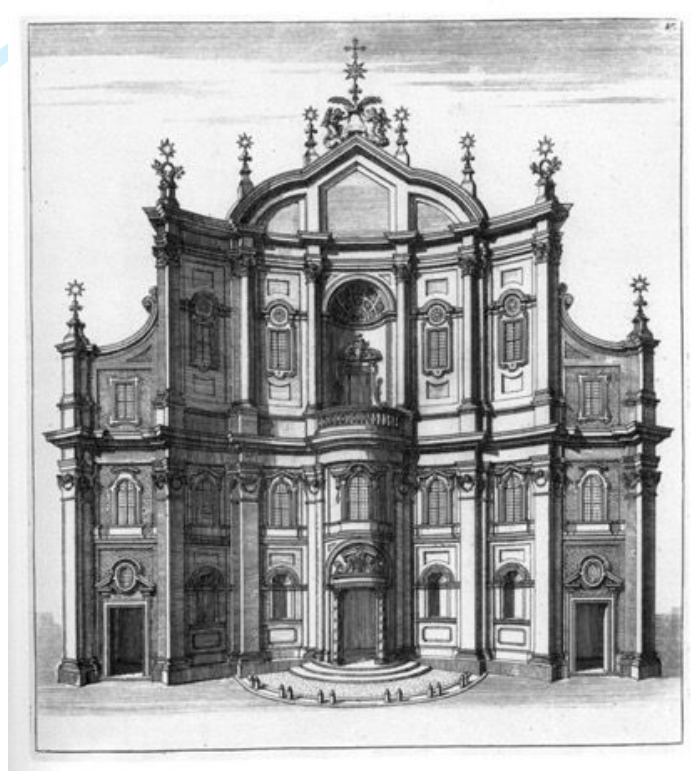

Figure 2. Engraving of the façade of Francesco Borromini's Oratorio dei Filippini by Domenico Barrière (1658). Retrieved from:

https://commons.wikimedia.org/wiki/File:Borromini_Drawing_01.jpg

Following the terminology guidelines proposed by Gómez-Puerto, Munar and Nadal (2016), we will refer to the characteristics of our stimuli as curved and sharpangled. We availed ourselves of the expertise of the architect S. Lamaddalena to create the stimuli for this study, using the professional software application AutoCAD (version 2.0, 2015). Together with her, we defined the architectural features to manipulate in the 
1. global: the overall shape and outline of the façade;

2. local: windows, columns and other decorative elements on the façade.

The final stimuli developed from these concepts consisted of four simplified 2D models of the reference building, whose global and local architecture features varied reflecting the following characteristics:

- A, curved;

- B, mixed;

- C, rectilinear;

- D, sharp-angled.

All religious references in the façades were removed, to avoid interactions with participants' religious affiliation.

One of the main predictions deriving from Berlyne's classical work on aesthetic experience, is that people tend to prefer medium levels of complexity (Berlyne, 1970), and we know from previous findings that sharp-angled shapes are judges as more complex compared to curved ones (Bertamini et al., 2016). Taking in account those evidences, we hypothesised the mixed façade (B) to be judged as having a medium level of complexity and, consequently, to be preferred over the other versions -being also the closest to the original design of the reference building. Bertamini et al. (2016) found that preference for patterns od simple lines was higher for the curved version, followed by rectilinear and sharp-angled. The rectilinear façade (C) was created as a control condition, in the attempt to replicate the findings by Bertamini et al. (2016) in the architecture domain. 

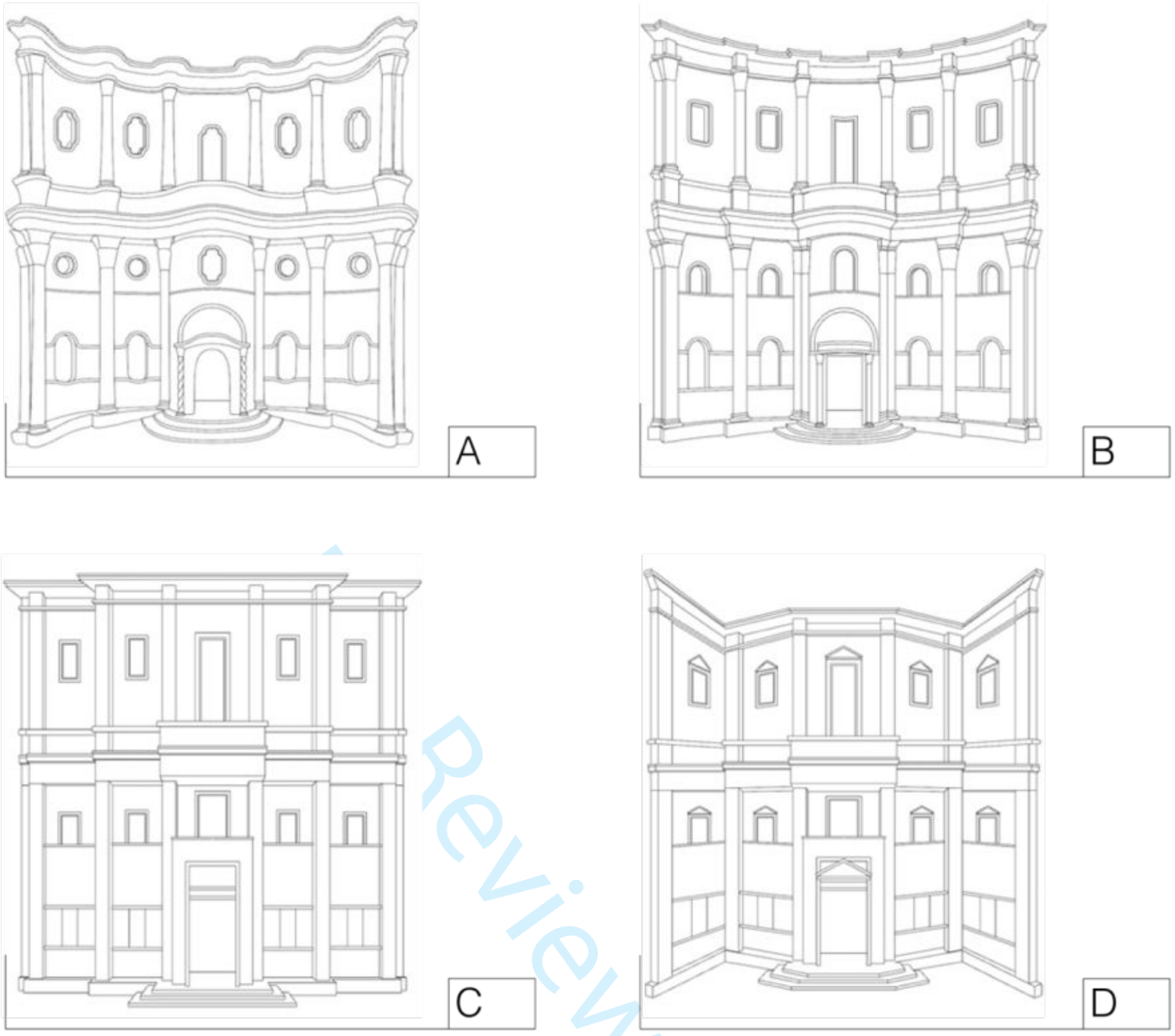

267

268

Figure 3. The four architectural façades we used in our study. In alphabetical order: curved (A), mixed (B), rectilinear (C) and sharp-angled (D) version.

\section{Procedure}

272 In order to simulate a more ecological situation, we presented the images of

273 architectural façades on a big projection screen rather than on a small computer

274 monitor. The experimental apparatus consisted of a $150 \mathrm{~cm}$ x170 cm projection screen

275 in a darkened classroom. All participants were seated at approximately $250 \mathrm{~cm}$ from the

276 screen. Stimuli were presented using an Epson Eh - tw5650 projector (2.500 lumen, full

277 HD, contrast at $60.000: 1$ ) and occupied $176^{\circ}$ of visual angle. During the experiment 
278 participants were not allowed to talk with each other and two researchers supervised the 279 room to guarantee the tasks to be performed accurately and independently.

Being aware of the conflicting results reported on expertise in preference for

281 curvature (Silvia \& Barona, 2009), we decided to control for expertise even if people in

282 our sample did not have any formal training in art. According to the model of aesthetic

283 appreciation outlined by Leder et al. (2004), we know that art interest plays an

284 important role in aesthetic appreciation. Before starting the experimental session, we

285 asked participants to self-assess their level of art interest on a five-point Likert scale

286 (where $5=$ "Very much" and $1=$ "Not at all") ${ }^{1}$, as a way of quantifying expertise

287 among non-experts.

The current study consisted of three experimental blocks. Each block was associated with a customised printed grid, as described below in more detail. The main aim of our procedure was to test if preference for curvature is task-independent.

The first block consisted of a two-alternatives forced choice task. We presented for 3 seconds each of all the possible six combinations of the four façades, without repetitions: $\mathrm{AB} ; \mathrm{CD} ; \mathrm{BC} ; \mathrm{AD} ; \mathrm{CA} ; \mathrm{DB}$. Each façade was presented three times in total and the order was counterbalanced, to make sure that each version appeared at least once on the left-hand side of the projection screen. After the stimuli disappeared the screen was blanked, and participants were asked to record their preferred façade on a

297 printed grid. The grid consisted of six rows, one for each repetition, and were divided

298 into two cells. If participants preferred façade presented on the left-hand side of the 299 screen, they were asked to tick the left cell on the printed grid; if they preferred the 300 façade on the right-hand side, to tick the right cell.

301 During the second block, participants performed a multiple rating task. They 302 were asked to rate each façade using a five-point Likert scale (where 1 = "not at all", 2 
$303=$ "slightly", $3=$ "somewhat", $4=$ "moderately" and 5= "very much" $)$. The façades

304 were presented on screen one at the time and were identified by a letter previously

305 assigned by the researchers, as illustrated in Figure 3. Participants were asked to collect

306 ratings on a customised printed greed for five psychological dimensions: liking,

307 familiarity, complexity, stability and approach ${ }^{2}$. Participants performed the liking

308 ratings first, to assure that liking would not be affected by the other measures.

309 Finally, in the third block participants had to perform a rating task. The four

310 façades were presented all at the same time on screen, arranged as shown in Figure 3.

311 Each stimulus was identified by the same letter as the one used in the second. The

312 customised grid consisted of four squares, arranged in a row. Participants had to fill the

313 squares with the letters identifying each stimulus, arranging the façades from the most

$314 \quad(=1)$ to the least $(=4)$ preferred.

\section{Data analysis and Results}

316 Due to the nature of our procedure, we report the results from the three different

317 experimental blocks separately.

\section{First block: two-alternatives forced choice}

319 The results of the two-alternatives forced choice experiment are summarized in the

320 dominance matrix reported in Table 1: each positive entry represents the number of

\footnotetext{
${ }^{1}$ Original items in Italian were: 1 = "per niente", 2 = "poco", $3=$ "abbastanza", 4 = "molto" and $5=$ "moltissimo"

${ }^{2}$ Original items in Italian were: "Quanto ti piace questo edificio?" "Quanto ti è familiare questo edificio?"; “Quanto è complesso questo edificio?"; "Quanto è stabile questo edificio?"; “Quanto questo edificio ti invita ad entrare?".
} 
321 times the row façade was preferred to the column façade, and main diagonal elements

322 are conventionally set to zero. All the corresponding off-diagonal elements satisfy a constant sum property (e.g.: all pairs of corresponding entries $(i, j)$ and $(j, i)$ sum up to 24), resulting in the sum of row and column totals for each façade being also constant. Thanks to this way of representing data, we can easily obtain the façades preference order by the row totals of the dominance matrix, that is -from the most to the less preferred:

- A (curved);

- B (mixed);

- D (sharp-angled);

- $\mathrm{C}$ (rectilinear).

A second consequence of the previous properties is that symmetry is not

333 interesting in this matrix, but it is worthwhile to focalize on the skew-symmetric

334 information. The skew-symmetry of each pair of façades is the difference of the

335 corresponding frequency in the matrix by the value 12 , which in our experiment

336 corresponds to the situation of equilibrium (12 subjects prefer one façade and other 12

337 subjects prefer the other one).

\begin{tabular}{lllll}
\hline Façades & A & B & C & D \\
\hline A & - & 21 & 22 & 21 \\
B & 3 & - & 19 & 17 \\
C & 2 & 5 & - & 6 \\
D & 3 & 7 & 18 & - \\
\hline
\end{tabular}

Table 1. The table reports the dominance matrix for the paired-comparison task. 
The skew-symmetric component of a dominance matrix can be depicted by a

340 method of asymmetric multidimensional scaling proposed by Bove $(2011,2012)$, which

341 adapted the idea originally proposed by Okada \& Imaizumi (1987) for asymmetric

342 proximities to skew-symmetric data. This method represents the architectural façades as

343 points in a two-dimensions diagram. Both the façade preference orders and the

344 imbalances are represented: the former as circles with different radii (larger circles

345 correspond to higher ranks of preference), the latter as the distances between points

346 (larger distances correspond to lower equilibrium). Results are shown in Figure 4.

347 The size of the circles shows the overall preference order: A, B, D, C. Façade A

348 is the most preferred and is liked equally more than B, C and D. Façades B and D have

349 the smallest imbalance between each other, so they are represented as closer on the

350 plane. Façade $\mathrm{C}$ is the last on the preference order with no ray. It is dominated by all the

351 other façades, but much more by A and B that are positioned further away from it.

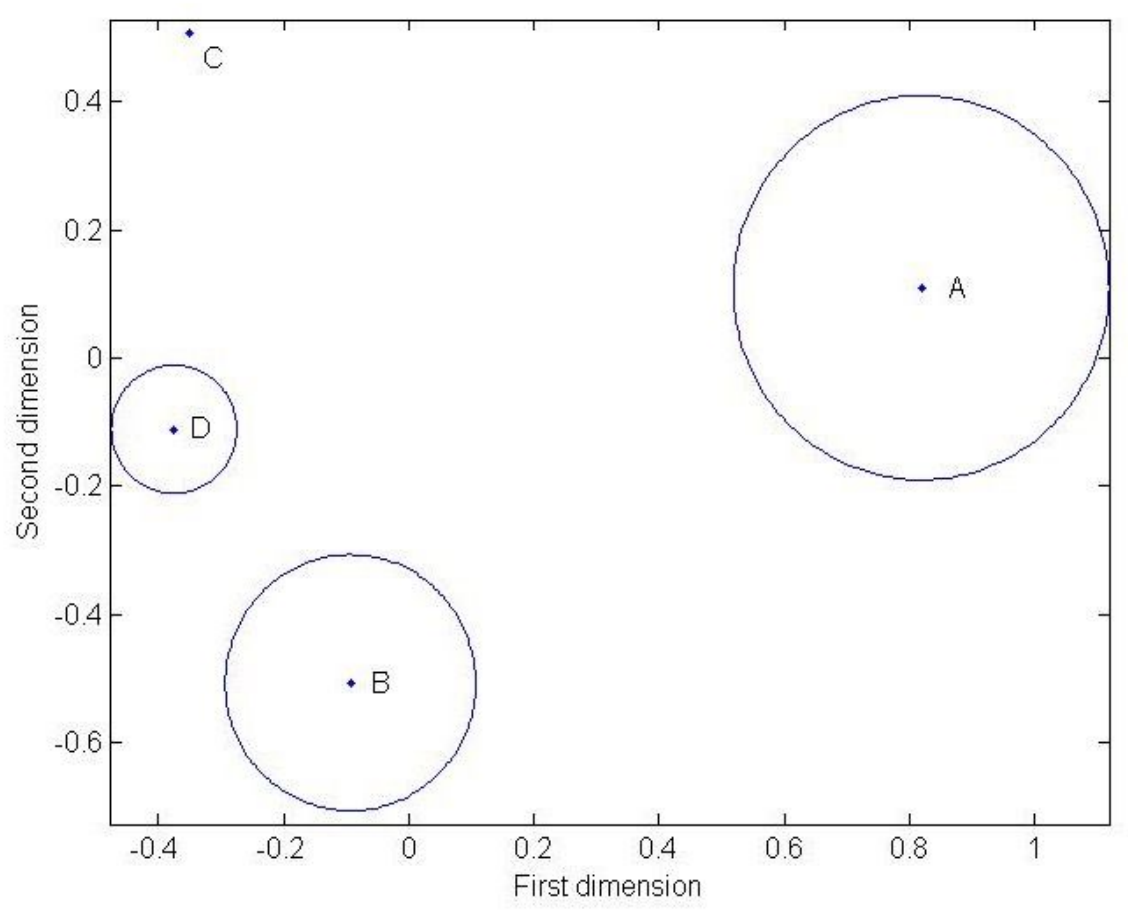

353 Figure 4. Asymmetric multidimensional scaling representation for data in Table 1. 


\section{Second block: multiple rating tasks}

355 Five one-way repeated measure ANOVAs were conducted on rating values for each of

356 the five psychological variables we measured (liking, approach, complexity, stability

357 and familiarity), with façade version (A, B, C and D) as independent variable. There

358 was no significant difference for familiarity ratings $(\mathrm{F}(3,69)=2.375, p=.078 \mathrm{NS})$,

359 suggesting that the simple design of our stimuli did not interfere with the perceived

360 familiarity of the architectural style of the façades. All the other psychological

361 dimensions had a statistically significant main effect: liking $(F(3,69)=13.077, p=.000)$,

362 approach $(\mathrm{F}(3,69)=12.375, p=.000)$, complexity $(\mathrm{F}(3,69)=13.162, p=.000)$ and

363 stability $(\mathrm{F}(3,69)=3.060, p=.034)$.

364 Post hoc tests using the Bonferroni correction revealed that liking $(1.8 \pm 0.35)$,

365 approach $(2.08 \pm 0.37)$ and complexity $(2.3 \pm 0.22)$ mean ratings for the rectilinear

366 façade - C - were statistically significantly lower than mean ratings for the other

367 façades $(p<.05)$. It is relevant to report the façades' rating order for each of the

368 measured variables, from the most to the least rated:

369 - A, D, B, C for liking and approach;

$370 \quad$ - D, A, B, C for complexity;

$371 \quad$ - C, B, A, D for stability. 
Curvature and sharpness in architectural façades
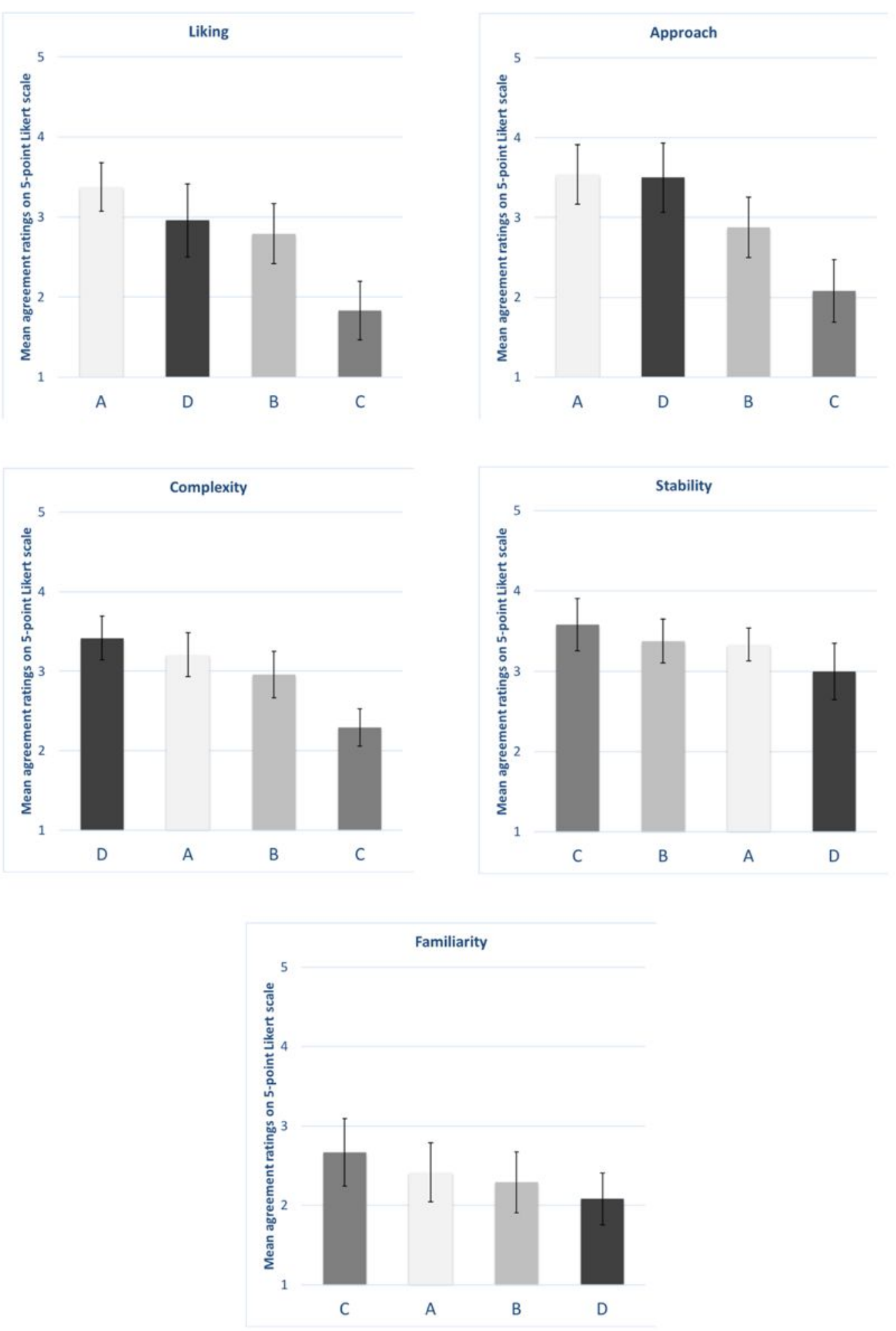

373 Figure 5. The graphs show the average score obtained by each building across the five 374 variables. From top to bottom, left to right: liking, approach, complexity, stability and 375 familiarity -bottom middle-. Error bars represent confidence intervals. 


\section{Third block: ranking task}

377 The analysis of the frequencies we collected for the ranking task confirmed the

378 preference order showed in the two-alternatives forced choice task as the ranking order 379 was A, B, D and C. Table 2 reports the number of times each façade (row) was chosen 380 in an order position (column) by participants.

\begin{tabular}{lcccc}
\hline & First & Second & Third & Fourth \\
\hline A & 15 & 5 & 3 & 1 \\
B & 5 & 13 & 6 & 0 \\
C & 1 & 0 & 2 & 21 \\
D & 3 & 6 & 13 & 2 \\
\hline
\end{tabular}

381 Table 2. The table reports the frequencies of order choices in the ranking task.

382

383

384

385

386

Besides, we analysed the $(24 \times 4)$ preference data matrix with multidimensional unfolding technique (Borg \& Groenen, 2005) to explore possible relationships between subjects and façades. The results from this analysis are shown in Figure 6, where numbers represent the subjects and letters represent the façades.

According to the properties of the unfolding representation, the subjects tend to be closer to the façades for which they expressed a higher rank in the task. Overall, façade $\mathrm{A}$ - curved - and to a less extent façade $\mathrm{B}$ - mixed - are the two main buildings around which the gather majority of the subjects is placed, including the one with the highest self-reported artistic interest. Subjects 4,9 and 15 preferred façade D, but their artistic interest rank was of 2, corresponding to a medium-low level. Only one subject (subject 14) preferred façade C, but had also the lowest level of artistic interest, corresponding to no artistic interest at all. 


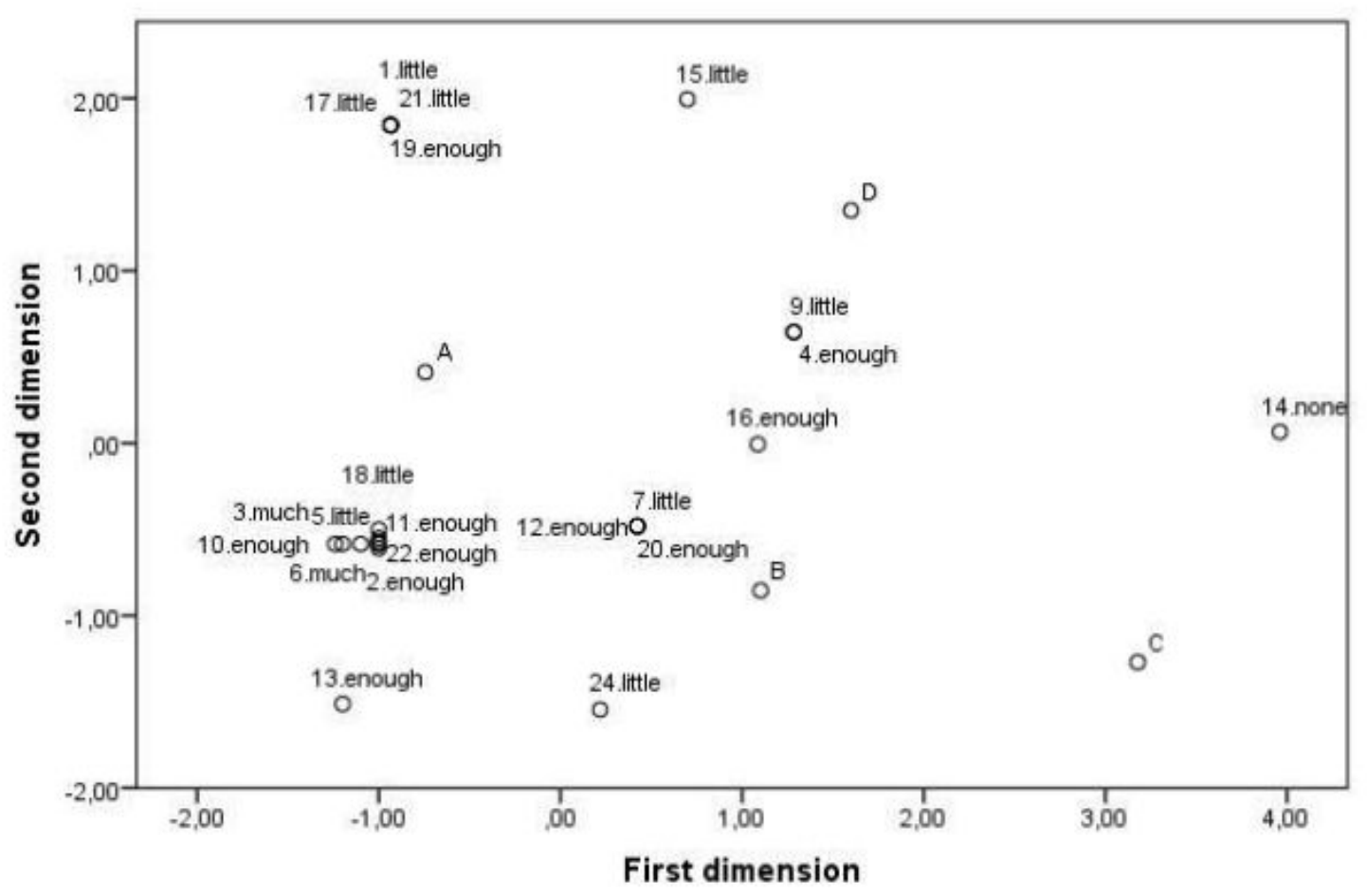

397 Figure 6. Multidimensional unfolding representation for rank order scores (Subject

398 artistic interest level labels: none, little, enough, much).

399 Results from Image analysis

400 We used a model developed in Penacchio and Wilkins (2015) to analyse the stimuli.

401 According to Fourier analysis, images can be decomposed into a sum of waves with

402 different orientations, amplitudes and wavelengths -or spatial frequency. The amplitude

403 of these waves as a function of spatial frequency is called the amplitude spectrum of an

404 image. Natural images consistently have a very specific relationship between amplitude

405 and spatial frequency: amplitude is proportional to the inverse of spatial frequency, a

406 property often referred to as $1 / \mathrm{f}$, where $\mathrm{f}$ stands for spatial frequency. This means that

407 low frequencies have much more energy (or contrast) than high frequencies in natural

408 images and that the fall-off statistically obeys the $1 / \mathrm{f}$ rule. The model we used

409 essentially computes the extent to which an image amplitude spectrum departs from $1 / \mathrm{f}$. 
410 The model can also take into account anisotropy, the excess of energy that horizontal

411 and vertical frequencies have in natural scenes and to which the visual system has

412 adapted across evolution. Finally, when comparing the amplitude spectrum of an image

413 to the typical amplitude spectrum of natural images, the model can give more weight to

414 the spatial frequencies the human visual system is most sensitive to, namely frequencies

415 around three cycles per degree (Campbell, 1968). Given an image, the model therefore

416 provides a single number, called residual, that measures the extent to which the image

417 deviates from the natural spectrum of natural images for a visual system differentially

418 sensitive to some spatial frequencies. The lower the residual, the more similar to natural

419 images the stimulus is. The model based on fundamental principles in efficient coding is 420 a good predictor of visual discomfort (Penacchio \& Wilkins, 2015).

The four different versions of the model (depending on whether anisotropy and the human sensitivity to different spatial frequencies are taken in to account) gave the same order of departure from natural images (i.e., the same order for the residuals): A (4.4), B (6), D (7.4), C (9). (The numbers reported here correspond to the residuals for the most general version of the model, see Penacchio and Wilkins, 2015.) The same order was also predicted by a mathematical model of the cortex. We processed the

427 images with a mechanistic neurodynamical model of the visual cortex that includes the 428 fundamental machinery underlying contextual modulation, namely excitatory and inhibitory neurons sensitive to different orientations as found in the primary visual 430 cortex and lateral connections between them (Zhaoping Li 2002, Penacchio et al. 2013).

431 The activity of this mechanistic model, which has been shown to encode comfortable 432 images with a sparse activity (requiring only few neurons to fire strongly at the same 433 time, as the visual cortex does in the presence of natural images) and uncomfortable 434 images with a dense activity (Penacchio et al. 2016), ranked A, B, D and C, in 
435 conformity with the model based on Fourier analysis, and in line with a general theory

436 of aesthetics based on the sensory coding of natural stimuli (Redies, 2007) and in line

437 with the behavioural data.

\section{Discussion}

Our findings confirmed that curvature influenced preferences also for the stimuli

440 representing architectural façades created for this study. Multidimensional scaling and

441 unfolding provided graphical representations to easily detect preference order, size of asymmetry and relationships between subjects and stimuli (Maydeu-Olivares \&

Bockenholt, 2009; Piccolo, 2006). When participants directly compared different

444 versions of the same building, the curved façade was the most preferred, followed by

445 the mixed, sharp-angled and rectilinear, both in the two-alternatives forced choice

446 (2AFC) and the ranking task. In both cases, the rectilinear stimulus was the least

447 preferred and not the sharp-angled stimulus, as found in the previous study by

448 Bertamini et al. (2016), that used patterns of simple lines. It is important to report that

449 previous findings showed that different exposure time can modulate the curvature effect

450 (Bar and Neta, 2006, 2007; Bertamini \& Palumbo, 2016, Munar et al., 2015). The focus

451 of the present study was to replicate those previous findings in the architecture domain.

452 The aim for future research is to include different exposure time, to investigate the

453 critical time span in which curvature has a significant effect in driving aesthetic

454 preference, in modulating affective or emotional state and in influencing social

455 behaviour.

456 The four architectural façades generated for this study were processed with the

457 model described above (Penacchio and Wilkins, 2015) and with a dynamical model of

458 the visual cortex (Penacchio, Otazu \& Dempere-Marco, 2013, Penacchio et al. 2016).

459 The order of stimuli preference was related in both models and matched to the 
460 behavioural data collected in this study and previous findings (Redies, 2007; Penacchio 461 and Wilkins, 2015).

The hypothesis that preference for curvature derives from the optimal

stimulation of the visual system might by itself explain this effect (Gómez-Puerto et al.

2016). We suggest creating a link between the statistical properties of natural scenes

and that preference for curvature might have evolved from human interaction with

natural environments. In support of this hypothesis, we report the interesting perceiving threat but, more easily, to the basic perceptual mechanisms involved in detecting the curvilinear shape of those animals. Results from this study showed that participants were faster in detecting simple curvilinear shapes - so called snake-like stimuli- compared to their rectilinear counterpart, even in the absence of any threatrelated information (LoBue, 2014). Our results seem to suggest that the image analysis approach used in the current study could be a valid way of quantifying curvature, which seems to be connected with predicted levels of image discomfort. We hope to better validate this methodology in future research, processing a richer set of stimuli and architectural styles, to investigate this link and its interaction with culture and expertise. and familiarity showed a slightly different pattern and generated interesting insight.

480 Both for liking and approachability the curved façade reported the highest ratings,

481 followed by the sharp-angled version, which gained the second position over the mixed 482 façade compared to the ranking and forced-choice tasks. The sharp-angled façade was 483 judged as being the most complex, while the rectilinear the most stable. Previous 484 findings reported that curvature did not affect approach-avoidance decisions for 
485 architectural interiors (Vartanian et al., 2013, 2015), however this was not the case for

486 our study. We advance three possible explanations for these findings:

1) people might judge exterior prospects in a different way compared to interior

living spaces and a better understanding of the psychological variables involved in

approach-avoidance decisions is needed, in order to revise classical explanations -like

perspective-refuge theory — and to stimulate interdisciplinary research;

2) the curved and the sharp-angled façades - those two showing the deepest gap

between the central part and the extremes lateral corners of the façade - might have

been perceived as physically projecting more towards the viewer compared to the other

two versions, increasing the perceived approachability of the building for curved and sharp-angled version (see Fig. 2);

3) the rating order might have been influenced by the affective valence of the

Results from this study present two main implications on future research:

(1) they provide empirical support for the hypothesis that preference for curvature might be stronger if compared to rectilinear rather than to sharp-angled features or stimuli presenting different amount of curvature;

(2) they shed light on the nature of human preferences, intrinsically dynamic and influenced by context and experience.

507 sample of architectural stimuli, making hard to draw any more general conclusions.

508 Following an emerging approach in current research of controlling the aesthetic

509 qualities of stimuli (Leder \& Carbon, 2005; Shemesh et al., 2016), future studies will 
510 aim to produce a more varied sample of architectural styles in order to investigate

511 perceived approachability of interiors compared exteriors architectures, the role of

512 buildings' function and cross-cultural differences, including measures like perceived

513 innovativeness, interest (Carbon and Leder, 2005) or embodiment.

514 It is not hard to imagine that negative aesthetic reactions might be voluntarily

515 induced by architects when designing buildings, using particular shapes and geometry.

516 The 'Jewish Museum Berlin' (1989-2001) designed by Daniel Libeskind is an example

517 of an architecture design that aims to induce a sense of fear, discomfort and dramatic

518 absence in the visitor rather than liking or positive feelings. Knowing the critical role

519 played by expertise in influencing curvature preference we suggest that architectural

520 design practice might benefit from collaborating with scientific research, to better

521 predict human perceptual as well as emotional reactions to the shape and geometry of

522 buildings, aiming to plan better cities.

523

524 Disclosure statement

$525 \quad$ No potential conflict of interest was reported by the authors.

526 ORCID

527 Nicole Ruta: https://orcid.org/0000-0001-5300-2913

528 Stefano Mastandrea: https://orcid.org/0000-0001-5128-1525

529 Olivier Penacchio: https://orcid.org/0000-0002-1544-2405

$530 \quad$ Giuseppe Bove: https://orcid.org/0000-0002-2736-5697

\section{References}

532 Aguilar, Javier Senosiain. Bio-architecture. Routledge, 2003. 
533 Alberti, Leon Battista. 1972. Leon Battista Alberti: On painting (De Pictura).

534 Translated and edited by Grayson, Cecil. London: Phaidon. (Original work published 535 1436).

536 Appleton, Jay. 1992. "Prospects and refuges re-visited.” In Environmental aesthetics:

537 Theory, research, and application, edited by Nasar, Jack L., 27-44, Cambridge

538 University Press.

539 Appleton, Jay. The experience of landscape. Chichester: Wiley, 1996.

540 Bar, Moshe, Maital Neta, and Heather Linz. "Very first impressions." Emotion 6, no. 2

541 (2006): 269.

542 Bar, Moshe, and Maital Neta. "Visual elements of subjective preference modulate

543 amygdala activation." Neuropsychologia45, no. 10 (2007): 2191-2200.

544 Berlyne, Daniel E. "Novelty, complexity, and hedonic value." Perception \&

545 Psychophysics 8, no. 5 (1970): 279-286.

546 Bertamini, Marco, Letizia Palumbo, Tamara Nicoleta Gheorghes, and Mai Galatsidas.

547 "Do observers like curvature or do they dislike angularity?." British Journal of

$548 \quad$ Psychology107, no. 1 (2016): 154-178.

549 Borg, Ingwer, and Patrick JF Groenen. Modern multidimensional scaling: Theory and 550 applications. Springer Science \& Business Media, 2005.

551 Bove, Giuseppe. "Analysis of skew-symmetry in proximity data." In New Perspectives

552 in Statistical Modeling and Data Analysis, pp. 203-210. Springer, Berlin, Heidelberg, 5532011.

554 Bove, Giuseppe. " Exploratory approaches to seriation by asymmetric multidimensional 555 scaling." Behaviormetrika 39, no. 1 (2012): 63-73.

556 Campbell, Fergus W., and J. G. Robson. "Application of Fourier analysis to the

557 visibility of gratings." The Journal of physiology 197, no. 3 (1968): 551-566. 
558 Carbon, C. Christian, and Leder, Helmut "The repeated evaluation technique (RET). A

559 method to capture dynamic effects of innovativeness and attractiveness." Applied

560 Cognitive Psychology: The Official Journal of the Society for Applied Research in

561 Memory and Cognition, (2005): 19(5), 587-601.

562 Carbon, Claus-Christian. "The cycle of preference: Long-term dynamics of aesthetic

563 appreciation." Acta psychologica 134, no. 2 (2010): 233-244.

564 Chirumbolo, Antonio, Ambra Brizi, Stefano Mastandrea, and Lucia Mannetti. "‘Beauty

565 Is No Quality in Things Themselves': Epistemic Motivation Affects Implicit

566 Preferences for Art." PloS one 9, no. 10 (2014): e110323.

567 Dosen, Annemarie S., and Michael J. Ostwald. "Evidence for prospect-refuge theory: a

568 meta-analysis of the findings of environmental preference research." City, Territory and

569 Architecture 3, no. 1 (2016): 4.

570 Fantz, Robert L., and Simon B. Miranda. "Newborn infant attention to form of

571 contour." Child Development (1975): 224-228.

572 Fernandez, Dominic, and Arnold J. Wilkins. "Uncomfortable images in art and

573 nature." Perception 37, no. 7 (2008): 1098-1113.

574 Field, David J. "Relations between the statistics of natural images and the response

575 properties of cortical cells." Josa a4, no. 12 (1987): 2379-2394.

576 Gann, David, Ammon Salter, and Jennifer Whyte. "Design quality indicator as a tool for

577 thinking." Building Research \& Information 31, no. 5 (2003): 318-333.

578 Geisler, Wilson S. "Visual perception and the statistical properties of natural

579 scenes." Annu. Rev. Psychol. 59 (2008): 167-192.

580 Gendall, John. "Biomimicry: Architecture That Imitates Life." Harvard

581 Magazine (2009). 
582 Gómez-Puerto, Gerardo, Enric Munar, and Marcos Nadal. "Preference for curvature: A

583 historical and conceptual framework." Frontiers in human neuroscience 9 (2016): 712.

584 Gutman R (ed) (2009) People and buildings. Transaction, London Hagerhall CM (2000)

585 Clustering predictors of landscape preference in the traditional Swedish cultural

586 landscape: prospect-refuge, mystery, age and management. J Environ Psychol 20(1):83-

$587 \quad 90$

588 Haigh, Sarah M., Laura Barningham, Monica Berntsen, Louise V. Coutts, Emily ST

589 Hobbs, Jennifer Irabor, Eleanor M. Lever, Peter Tang, and Arnold J. Wilkins.

590 "Discomfort and the cortical haemodynamic response to coloured gratings." Vision

591 research 89 (2013): 47-53.

592 Hibbard, Paul B., and Louise O'Hare. "Uncomfortable images produce non-sparse

593 responses in a model of primary visual cortex." Royal Society open science 2, no. 2

594 (2015): 140535.

595 Hildebrand, Grant. The Wright space: pattern and meaning in Frank Lloyd Wright's

596 houses. Seattle: University of Washington Press, 1991.

597 Hildebrand, Grant. Origins of architectural pleasure. Univ of California Press, 1999.

598 Jadva, Vasanti, Melissa Hines, and Susan Golombok. "Infants' preferences for toys,

599 colors, and shapes: Sex differences and similarities." Archives of sexual behavior 39,

600 no. 6 (2010): 1261-1273.

601 Juricevic, Igor, Leah Land, Arnold Wilkins, and Michael A. Webster. "Visual

602 discomfort and natural image statistics." Perception 39, no. 7 (2010): 884-899.

603 Le, An TD, Jasmine Payne, Charlotte Clarke, Murphy A. Kelly, Francesca Prudenziati,

604 Elise Armsby, Olivier Penacchio, and Arnold J. Wilkins. "Discomfort from urban

605 scenes: Metabolic consequences." Landscape and Urban Planning 160 (2017): 61-68. 
606 Leder, Helmut, Benno Belke, Andries Oeberst, and Dorothee Augustin. "A model of

607 aesthetic appreciation and aesthetic judgments." British journal of psychology 95, no. 4 608 (2004): 489-508.

609 Leder, Helmut, and Claus-Christian Carbon. "Dimensions in appreciation of car interior 610 design." Applied Cognitive Psychology 19, no. 5 (2005): 603-618.

611 Leder, Helmut, Pablo PL Tinio, and Moshe Bar. "Emotional valence modulates the

612 preference for curved objects." Perception 40, no. 6 (2011): 649-655.

613 Lederman, Roy R., and Ronen Talmon. "Learning the geometry of common latent

614 variables using alternating-diffusion." Applied and Computational Harmonic

615 Analysis 44, no. 3 (2018): 509-536.

616 Lidwell, William, Kritina Holden, and Jill Butler. Universal principles of design,

617 revised and updated: 125 ways to enhance usability, influence perception, increase

618 appeal, make better design decisions, and teach through design. Rockport Pub, 2010.

619 Lippman, Peter C. Evidence-based design of elementary and secondary schools: A 620 responsive approach to creating learning environments. John Wiley \& Sons, 2010.

621 LoBue, Vanessa. "Deconstructing the snake: The relative roles of perception, cognition, 622 and emotion on threat detection." Emotion 14, no. 4 (2014): 701.

623 Maass, Anne, Ilaria Merici, Erica Villafranca, Rosaria Furlani, Elena Gaburro, Anna

624 Getrevi, and Margherita Masserini. "Intimidating buildings: can courthouse architecture 625 affect perceived likelihood of conviction?." Environment and behavior 32, no. 5 (2000): $626 \quad 674-683$.

627 Mastandrea, Stefano, Gabriella Bartoli, and Giuseppe Carrus. "The automatic aesthetic 628 evaluation of different art and architectural styles." Psychology of Aesthetics, Creativity, 629 and the Arts 5, no. 2 (2011): 126. 
630 Mastandrea, Stefano, and Fridanna Maricchiolo. "Implicit and explicit aesthetic

631 evaluation of design objects." Art \& Perception 2, no. 1-2 (2014): 141-162.

632 Maydeu-Olivares, Alberto, and Ulf Böckenholt. "Modeling preference data." The SAGE

633 handbook of quantitative methods in psychology (2009): 264-282.

634 McManus, I. Chris, and Wen Wu. "“The square is... bulky, heavy, contented, plain,

635 good-natured, stupid...”: A cross-cultural study of the aesthetics and meanings of

636 rectangles." Psychology of Aesthetics, Creativity, and the Arts 7, no. 2 (2013): 130.

637 Munar, Enric, Gerardo Gómez-Puerto, Josep Call, and Marcos Nadal. "Common visual

638 preference for curved contours in humans and great apes." PloS one 10, no. 11 (2015):

$639 \mathrm{e} 0141106$.

640 Okada, Akinori, and Tadashi Imaizumi. "Nonmetric multidimensional scaling of

641 asymmetric proximities." Behaviormetrika 14, no. 21 (1987): 81-96.

642 Palladio, Andrea. 1997. Andrea Palladio: The Four Books on Architecture. (I Quattro

643 libri dell'architettura.) Translated and edited by Tavernor, R., Schofield, R.,

644 Cambridge: MIT Press (Original work published 1570).

645 Palumbo, Letizia, and Marco Bertamini. "The curvature effect: A comparison between

646 preference tasks." Empirical Studies of the Arts 34, no. 1 (2016): 35-52.

647 Palumbo, Letizia, Nicole Ruta, and Marco Bertamini. "Comparing angular and curved

648 shapes in terms of implicit associations and approach/avoidance responses." PloS one

649 10, no. 10 (2015): e0140043.

650 Penacchio, Olivier, and Arnold J. Wilkins. "Visual discomfort and the spatial

651 distribution of Fourier energy." Vision research 108 (2015): 1-7.

652 Penacchio, Olivier, Arnold J. Wilkins, Xavier Otazu, and Julie M. Harris. 2016, August.

653 "Inhibitory function and its contribution to cortical hyperexcitability and visual

654 discomfort as assessed by a computation model of cortical function." In Perception 45, 
655 pp. 272-272. Olivers Yard, 55 City Road, London EC1Y 1SP, England: Sage

656 Publications LTD.

657 Penacchio, Olivier, Xavier Otazu, and Laura Dempere-Marco. "A neurodynamical

658 model of brightness induction in v1." PloS one 8, no. 5 (2013): e64086.

659 Piccolo, Domenico. "Observed information matrix for MUB models." Quaderni di $660 \quad$ Statistica 8 (2006): 33-78.

661 Reber, Rolf, Norbert Schwarz, and Piotr Winkielman. "Processing fluency and aesthetic 662 pleasure: Is beauty in the perceiver's processing experience?." Personality and social 663 psychology review 8, no. 4 (2004): 364-382.

664 Redies, Christoph. "A universal model of esthetic perception based on the sensory 665 coding of natural stimuli." Spatial vision 21, no. 1 (2007): 97-117.

666 Shaftoe, Henry. Convivial urban spaces: Creating effective public places. Earthscan, 6672012.

668 Silvia, Paul J., and Christopher M. Barona. "Do people prefer curved objects?

669 Angularity, expertise, and aesthetic preference." Empirical studies of the arts 27, no. 1 670 (2009): 25-42.

671 Sullivan, Louis H. "The tall office building artistically considered." Lippincott's $672 \quad$ Magazine 57, no. 3 (1896): 406.

673 Talmon, Ronen, Stéphane Mallat, Hitten Zaveri, and Ronald R. Coifman. "Manifold 674 learning for latent variable inference in dynamical systems." IEEE Transactions on 675 Signal Processing63, no. 15 (2015): 3843-3856.

676 Zhang, Ting, and Hua Dong. 'Human-centred design: an emergent conceptual model', 677 Include2009, Royal College of Art, April 8-10, 2009, London Include2009 proceedings 678 (2009). Retrieved from: http://www.hhc.rca.ac.uk/2084/all/1/proceedings.aspx 
679 Vartanian, Oshin, Gorka Navarrete, Anjan Chatterjee, Lars Brorson Fich, Jose Luis

680 Gonzalez-Mora, Helmut Leder, Cristián Modrono, Marcos Nadal, Nicolai Rostrup, and

681 Martin Skov. "Architectural design and the brain: effects of ceiling height and perceived

682 enclosure on beauty judgments and approach-avoidance decisions." Journal of

683 environmental psychology 41 (2015): 10-18.

684 Vartanian, Oshin, Gorka, Navarrete, Anjan, Chatterjee, Lars Brorson, Fich, Helmut,

685 Leder, Cristián, Modroño, Marcos, Nadal, Nicolai, Rostrup, and Martin, Skov. "Impact

686 of contour on aesthetic judgments and approach-avoidance decisions in

687 architecture." Proceedings of the National Academy of Sciences 110, no. Supplement 2

688 (2013): 10446-10453.

689 Vitruvius, Marcus Pollio. 1914. Translated by Morris, Hicky Morgan, Vitruvius: The

690 Ten Books on Architecture. (De Architectura.) Cambridge: Harvard University Press.

691 Retrieved from: http://www.gutenberg.org/files/20239/20239-h/20239-h.htm (Original

692 work published 15 B.C.).

693 Lloyd Wright, F. "The living city." New York: Horizon (1958).

694 Zajonc, Robert B. "Attitudinal effects of mere exposure." Journal of personality and

695 social psychology 9, no. 2p2 (1968): 1.

696 Zhaoping, Li, and Peter Dayan. "Pre-attentive visual selection." Neural Networks 19,

697 no. 9 (2006): 1437-1439. 


\begin{tabular}{lrrrr}
\hline & \multicolumn{1}{c}{ First } & Second & \multicolumn{1}{c}{ Third } & \multicolumn{2}{c}{ Fourth } \\
\hline A & 15 & 5 & 3 & 1 \\
B & 5 & 13 & 6 & 0 \\
C & 1 & 0 & 2 & 21 \\
D & 3 & 6 & 13 & 2 \\
\hline
\end{tabular}

higher res version

$199 \times 57 \mathrm{~mm}(300 \times 300$ DPI) 

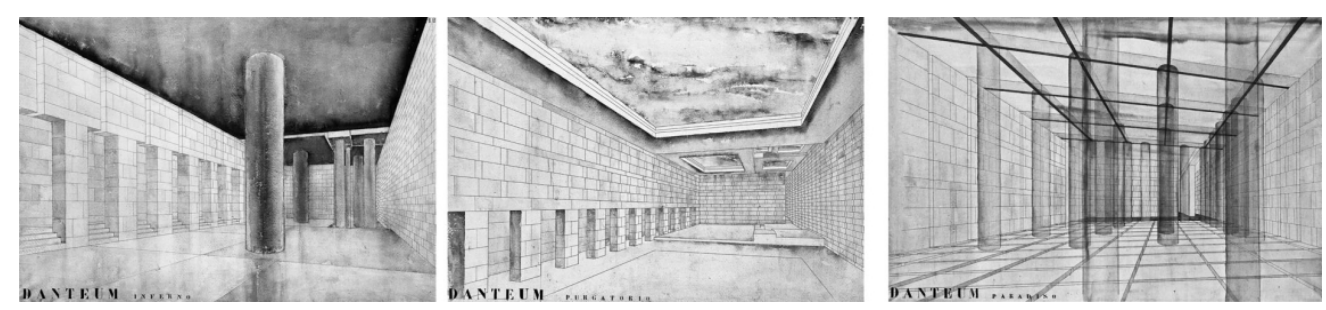

$160 \times 35 \mathrm{~mm}(300 \times 300$ DPI $)$ 


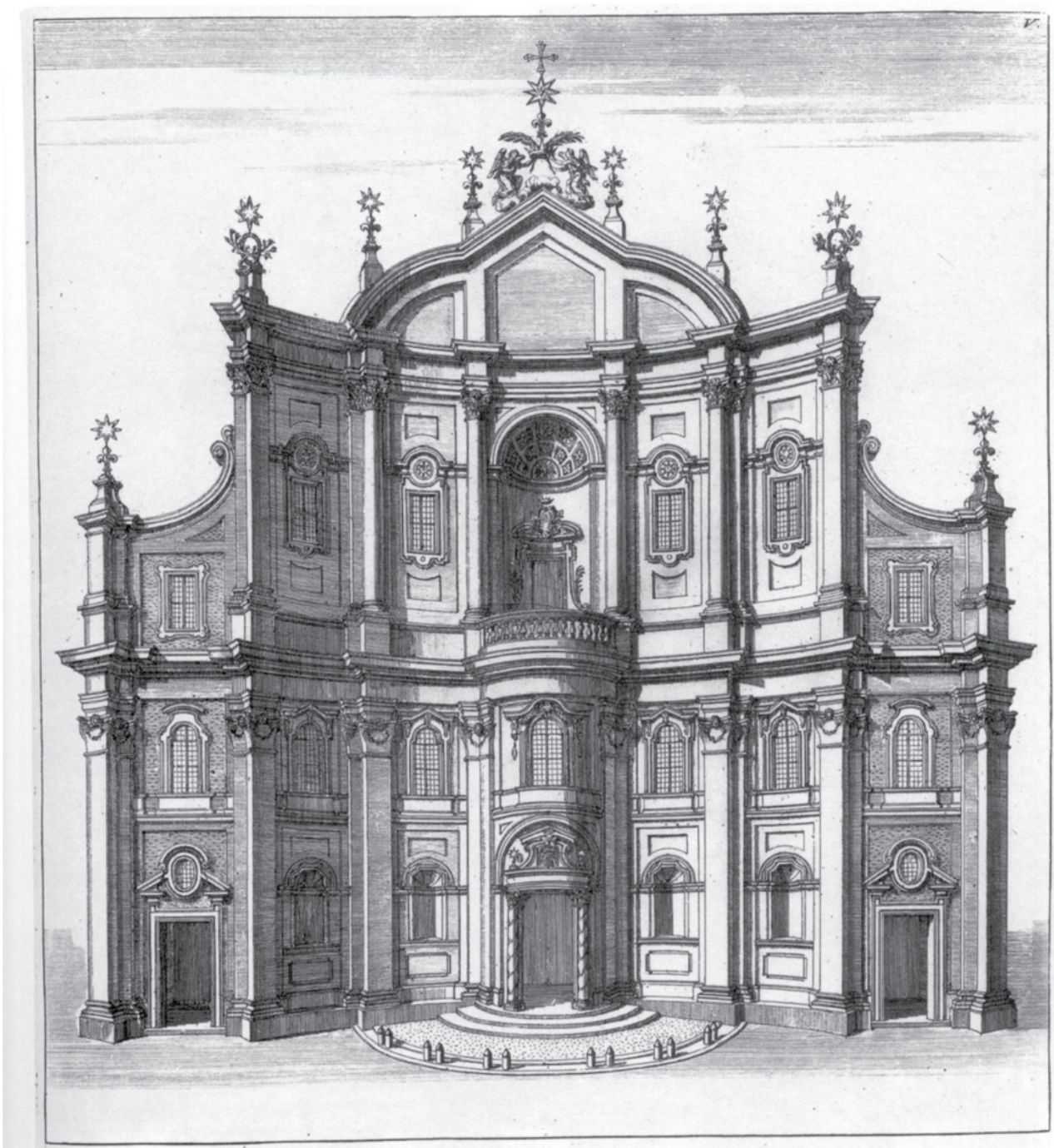

$80 \times 88 \mathrm{~mm}(300 \times 300 \mathrm{DPI})$ 

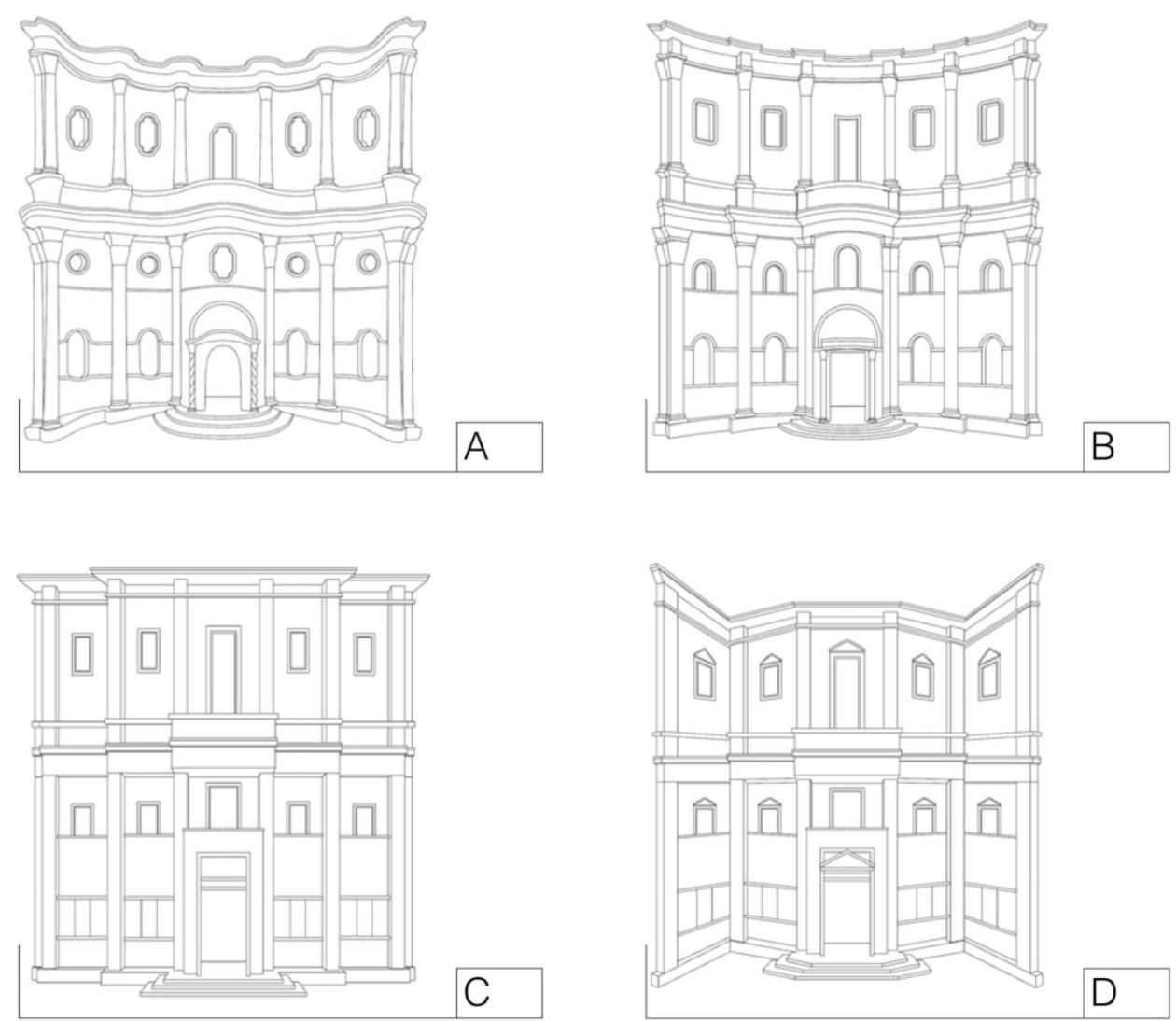

$133 \times 117 \mathrm{~mm}(300 \times 300$ DPI $)$

https://mc.manuscriptcentral.com/asre 


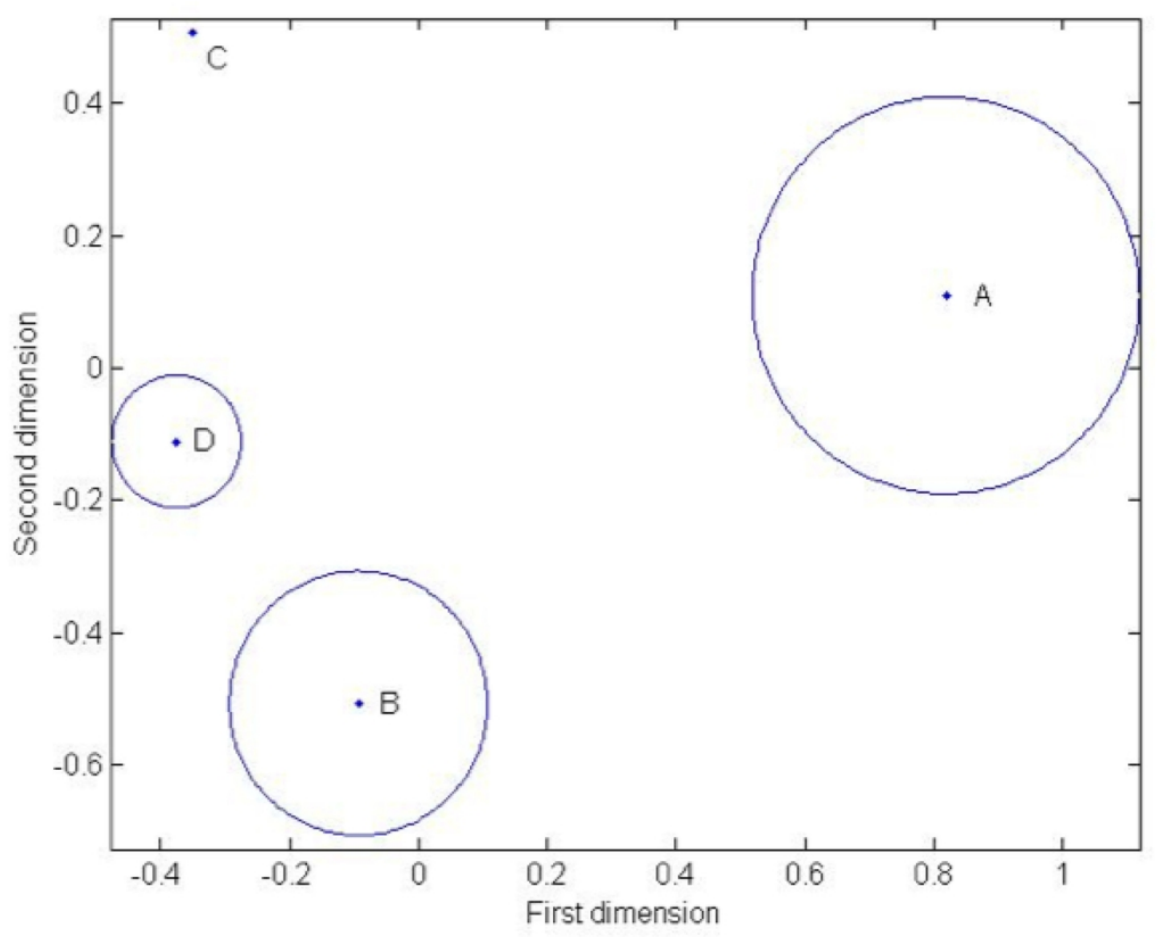

$125 \times 98 \mathrm{~mm}(300 \times 300 \mathrm{DPI})$ 

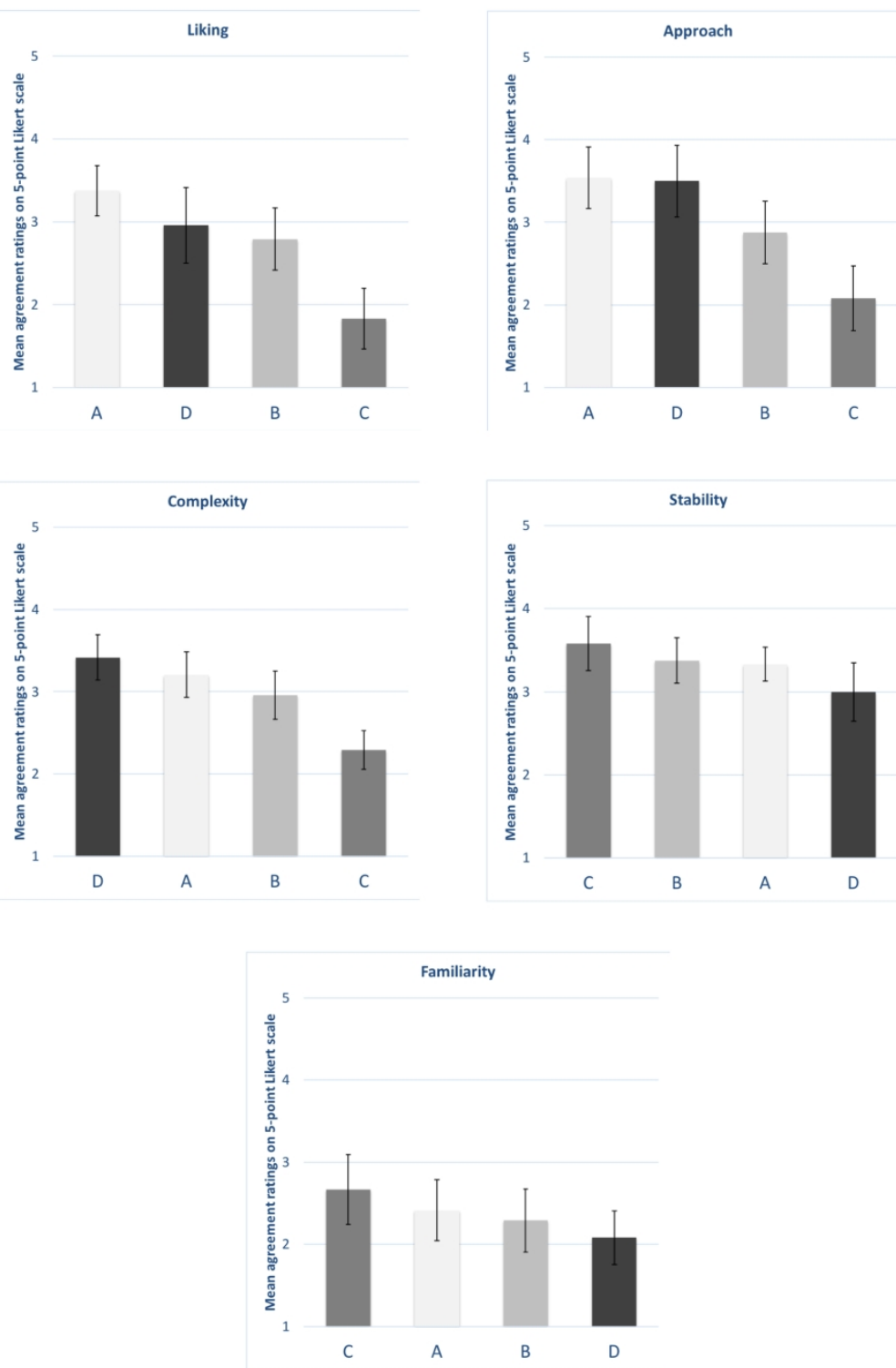

$199 \times 277 \mathrm{~mm}(300 \times 300 \mathrm{DPI})$ 


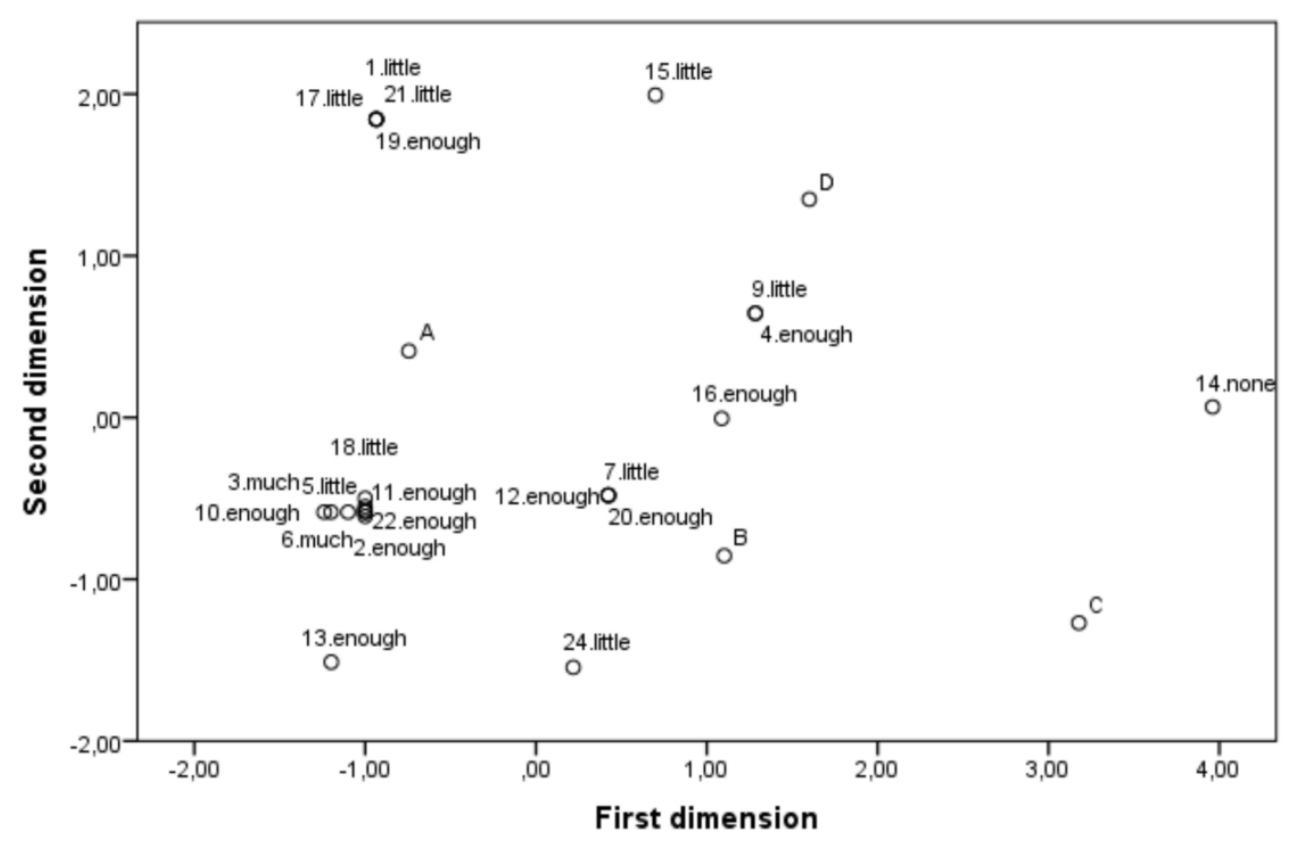

$199 \times 130 \mathrm{~mm}(300 \times 300$ DPI $)$ 